\title{
Delineation of the Flood Prone Zones Along the Medjerda Riv- er Downstream of Sidi Salem Dam in Tunisia
}

\author{
Mohamed Djebbi
}

National Engineering School of Tunis, P.O. Box 37, Le Belvedere, 1002 Tunis, Tunisia

Received: March 3, 2010 / Accepted: February 24, 2012

\begin{abstract}
The surge of extreme flooding events in the lower valley of the Medjerda between 1993 and 2005 raised people's awareness to their effects. The main goal of this study is to delineate flood prone zones in response to the release of water volumes from Sidi Salem Dam, Tunisia. In order to achieve this goal, it was necessary to quantify the inflow flood hydrograph and characterise the geomorphology of the Medjerda River downstream the dam. The US Army Corps of Engineers HEC-RAS program was used to estimate the extent of floodplains associated with the released waters from the dam of Sidi Salem during historical and potential flooding events. The flood conveyances were calculated using surveyed topography, and HEC-RAS which was calibrated using site specific field data. The model output included water surface profiles. These profiles, coupled with a digital elevation model, were utilized to generate flood maps. Results showed a reduction of the main channel conveyance and overflows even for modest discharges. Data analysis proved that there were minor changes in the riverbed profile and the shape of the river's cross-sections resulting in slower flow rates and larger sediment load depositions. This variability in the geomorphology of the river suggests that the flow friction factor varied as well. It is therefore crucial to monitor this friction factor variability in order to adjust the hydraulic models for better performances and forecasting capabilities with respect to standard models forced with static friction parameters. The produced flood maps are of great importance for several end-users particularly those in charge of: i) flood
\end{abstract}

\footnotetext{
* Corresponding author: mohamed.Djebbi@enit.rnu.tn
}

control and mitigation, ii) hydraulic structure design and deployment along major rivers, and iii) urban planning in order to avoid construction in flood-prone areas. The accuracy of these maps can be further improved by taking into account the morphological changes of the riverbed during each flooding event.

Keywords: Medjerda River, Sidi Salem Dam, Digital Elevation Model, Flooding maps, HEC-RAS Model.

\section{Introduction}

Medjerda is the most important and longest river in Tunisia with a length of $484 \mathrm{~km}$ (Ben Mansoura et al, 2001). It originates in north-eastern Algeria, flows eastward to Tunisia, and then discharges to the Gulf of Utica in the Mediterranean Sea (Figure 1). Thirty two and sixty eight percent of The Medjerda basin $\left(23,700 \mathrm{~km}^{2}\right)$ are located in Algeria and Tunisia, respectively. The Medjerda water resources average one billion $\mathrm{m}^{3}$ year $^{-1}$ and it represents $37 \%$ of the surface water of Tunisia and $22 \%$ of the country's renewable water resources (Zahar et al, 2008). These resources are very important for agricultural water use in the Mejerda valley and for domestic water use for many large cities including the capital Tunis (Mlayah et al, 2009). The construction of Sidi Salem Dam substantially reduced the discharge of Medjerda, altered the morphology of the river, and increased the frequency of floods below the dam (Zahar et al, 2008). 
The Sidi Salem Dam has been in operation since 1982. It is the largest dam in Tunisia and constitutes the main part of the Northern Water Master Plan. It has an initial storage capacity of about $5.5 \times 108 \mathrm{~m}^{3}$ and a surface area of 4,300 hectares. It is also the largest dam in North Africa (Bouraoui et al, 2005). The reservoir receives most of its water from the Medjerda River. The drainage area of the dam is $18,250 \mathrm{~km}^{2}$. The purpose of the dam was to control and level off the inter-annual variable inflows to secure adequate domestic and agricultural irrigation water supply for the northern and central parts of the country, especially the metropolitan area of Tunis. Water from the dam is also used to cool several power plants. Although the dam has largely contributed to the development of the northern regions of Tunisia, it also had significant adverse implications on the environment due to the silting of its reservoir.

Since the construction of Sidi Salem Dam, the channel downstream has progressively become narrower (Zahar et al, 2008). After 20 years of operation, Sidi Salem reservoir has lost over a third of its original capacity due to siltation. This volume corresponds to an average rate of filling of $6.8 \times 106 \mathrm{~m}^{3}$ year-1 $^{-1}$ (Zar, 2004). To compensate for the loss in storage capacity due to saltation and in order to maintain consistent outflows, in 1995, the water intake tower crest was raised by $5 \mathrm{~m}$. Consequently, the volume formerly reserved for flood control in case of major events has been decreased since then by $210 \times 106 \mathrm{~m}^{3}$. This situation requires more vigilance during management of exceptional flooding events for at least two reasons: first, it is necessary to prevent overtopping of the embankment under extreme rainfall conditions; second, overflows released downstream should be managed with minimum damage to downstream sections of the river.

To compensate, at least partially, for the loss in volume formerly reserved for temporary storage of excess runoff, it was vital to have an accurate estimate of the expected inflows, before their arrival to the dam, to ensure sufficient time to open the outflow gates. The routing of excess inflows through Sidi Salem reservoir was then quantified and new management guidelines were established (Djebbi et al., 2005). Although these new management guidelines have been adopted, the risks of flooding downstream of the dam remained very high especially under extreme flooding conditions (Diebbi et al., 2006). These new management guidelines have additional negative consequences on the river's morphology downstream of the dam. The most problematic consequence is the decline of the river discharge in the main channel (Ghorbel, 1997). Moreover, field observations from two consecutive topographic studies (Ghorbel, 1996, and INAT et al., 2004) confirm that the main channel of Medjerda is undergoing significant morphological changes which mainly consist of sediment deposition and the main channel flow area reduction downstream of Sidi Salem's dam. The main consequence of the shrinking cross-sections is the reduction of the main channel discharge and, consequently, the increase of the frequency in overbank flooding (Zahar et al, 2008). As an example, before the construction of the dam, a flow of $760 \mathrm{~m}^{3} \mathrm{~s}^{-1}$ could easily pass flow under the Mouradi Andalousian bridge of Medjez El Bab without any overflow. In 2003, under the same bridge, 150 $\mathrm{m}^{3} \mathrm{~s}^{-1}$ could barely flow without flooding. Also, the events of
2003,2004 , and 2005, clearly highlighted the increase in the frequency of the Medjerda floods. These events proved that the risk of flood downstream of Sidi Salem Dam remained very high. They also emphasized the need for more reliable predictions of flood levels, which in turn call for more accurate simulations.

The main goal of this study is to estimate the extent of floodplain inundations, corresponding to Sidi Salem outflows, in order to create plans for flood warning and evacuation. The objective of these plans is to reduce the damage to the lowest possible level. Specific objectives of this work are: I) characterize the inflow flood hydrograph to Sidi Salem Reservoir; and II) evaluate the performance of HEC-RAS in flood performance.

\section{Materials and Methods}

\section{Study Area of Medierda River}

The studied river reach extends from the dam of Sidi Salem to the outlet of the river in the Mediterranean Sea, a distance of $162 \mathrm{~km}$ measured along the channel centerline (Figure 2). Within this reach, there are 15 bridges and 185 cross-sections for which surveyed channel geometry data are available. These cross-sections were examined twice, in 1996 (Ghorbal, 1997) and 2003 (INAT, 2004). Among 185 cross-sections, five were assessed more than two times because they are part of the hydrometric gauging stations that have been operating for several years and for which the rating curves have been periodically updated. These five hydrometric gauging stations are called, Slouguia, Medjez El Bab, El Herri, Bori Toumi and Jdaïda, which are 20.7, 40.0, 61.3, 72.9 and $107.7 \mathrm{~km}$ downstream from Sidi Salem Dam, respectively (the river cross-section at these stations was assessed more frequently than the rest of 180 cross sections as part of the periodical update of the rating curves of the river's flows).

The examination of the evolution of the cross sections showed that the sections of the Medjerda River downstream of the dam have been going through considerable morphological changes. For instance, there was substantial sediment deposition on the banks and severe erosion of the riverbed at the cross section of Slouguia's hydrometric station (Figure 3). The flow area was reduced by $14 \mathrm{~m}^{2}$ and the longitudinal slope decreased by $4 \%$ between 1993 and 1995, which changed the rating curves. Consequently, this resulted in a reduction of the discharge capacity of the river (Figure 4). The flow deceleration, which was the result of sediment deposition, accentuated the risk of overflow and contributed to the imbalance of the river's longitudinal profile in the absence of calibration and maintenance work.

The phenomena of erosion and sediment deposition, and the discharge reduction were not localized but included the entire river reach downstream of the dam (Zahar et al, 2008). The observed morphological changes for the Medjerda valley reach created conditions favorable for overflow and increased risks of flood. This was particularly the case when significant water flows were released from Sidi Salem Dam as a result of heavy rainfall storms.

It is very crucial to accurately and promptly predict the major flood events so that flood warnings are initiated on time and 
appropriate evacuation strategies are developed. To be able to accurately predict the location and the magnitude of a flood, one has to have high resolution topographic and current hydrometric databases. Such databases require substantial resources and take a long time to develop. Because of these serious limitations, reliable hydrological software, if well calibrated and validated, could be a viable alternative.

\section{Modelling of Medjerda Flood Flows}

HEC-RAS is a public domain model developed by the US Army Corp of Engineers. It performs one-dimensional steady and unsteady flow calculations on a network of natural or manmade open channels (USACE, 2002) which enable the model to be used for a broad range of flow conditions. The simulation results can be displayed in graphical form, i.e., longitudinal profile, sections, rating-curve, and in the form of tables.

\section{Model Description}

Under steady conditions, HEC-RAS predicts surface water profile calculations for a gradually varied flow. In addition, subcritical, supercritical, and mixed flow regime is simulated. Surface water profiles are computed using Bernoulli's equation in order to compute changes in energy from one cross section to the next with an iterative procedure. The energy head loss between two cross sections is comprised of friction losses and contraction or expansion losses. Friction losses are evaluated as the product of friction slope and the reach length between the two crosssections. The friction slope at each cross section is computed using Manning's equation. Contraction and expansion losses are evaluated by empirical equations.

For unsteady conditions, HEC-RAS routes simple open channel floods and simultaneously produces water level forecasts. It then combines flood forecasting and flood level determination. Flow

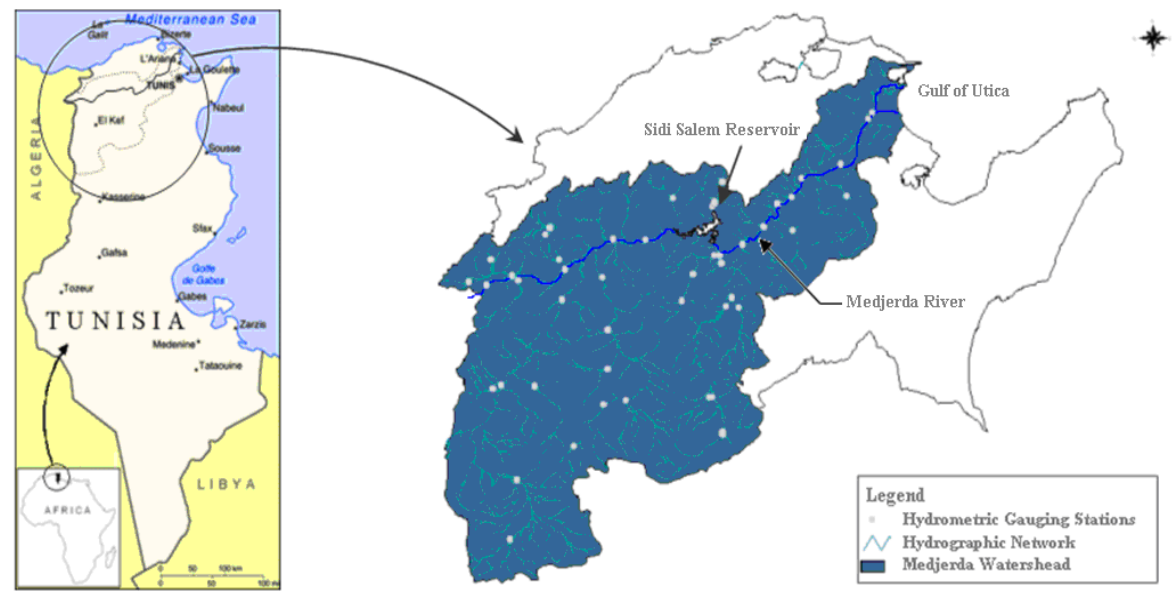

Figure 1. Location map, Medjerda River and Sidi Salem Dam.

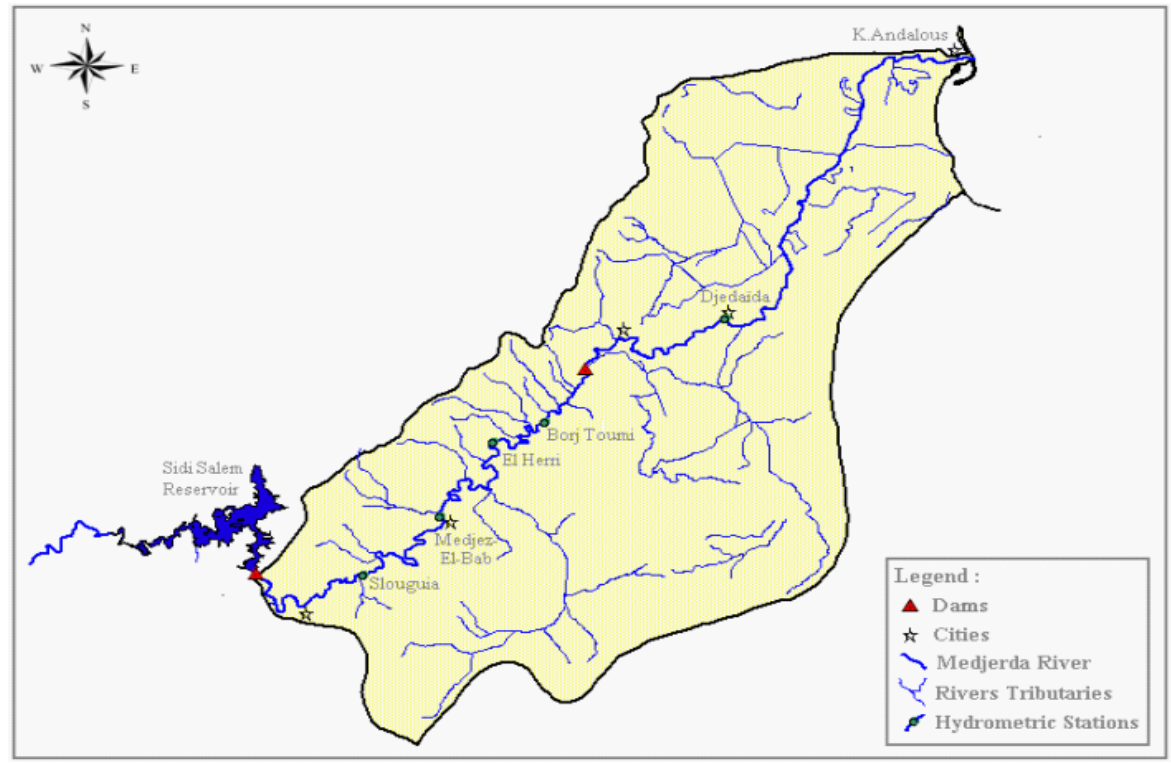

Figure 2. The map of the Medjerda River downstream of the Sidi Salem Dam. 
calculations are based on the continuity and momentum equations. A horizontal water surface at each cross-section normal to the direction of flow is assumed, such that the exchange of momentum between the channel and the floodplain is negligible and the discharge is distributed according to conveyance. The friction slopes are calculated from the values of the friction forces; the latters are part of Manning's flow equation. HEC-RAS solves Saint Venant's equations which are formulated for rivers and for natural channels as follows (USACE, 2002):

$$
\begin{aligned}
& \frac{\partial A}{\partial t}+\frac{\partial Q}{\partial x}=q_{l} \\
& \frac{\partial Q}{\partial t}+\frac{\partial\left(Q^{2} / A\right)}{\partial x}+g A \frac{\partial H}{\partial x}+g A S_{f}=q_{l} \\
& S_{f}=\frac{Q^{2} n^{2}}{R^{4 / 3} A^{2}}
\end{aligned}
$$

where $A$ is the cross-sectional area perpendicular to the flow $\left(\mathrm{m}^{2}\right) ; \mathrm{Q}$ is the discharge $\left(\mathrm{m}^{3} \mathrm{~s}^{-1}\right) ; \mathrm{ql}$ is the lateral inflow due to tributary $\left(\mathrm{m}^{2} \mathrm{~s}^{-1}\right) ; \mathrm{g}$ is the acceleration due to gravity $\left(\mathrm{ms}^{-2}\right) ; \mathrm{H}$ is the elevation of the water surface above a specified datum $(\mathrm{m})$, also called stage; $\mathrm{Sf}$ is the longitudinal boundary friction slope(need units); $n$ is the Manning roughness coefficient; $R$ is the hydraulic radius, A divided by the wetted perimeter of the channel $(\mathrm{m}) ; \boldsymbol{t}$ is the temporal coordinate(need units); and $\mathrm{x}$ is the longitudinal coordinate(need units).

The value of the Manning's roughness coefficient ( $n$ ) in Equation 3 is readily available from the literature. However, this coefficient depends on so many factors that it is difficult to accurately determine its value (Chow, 1959). This coefficient is usually considered as a calibration parameter for many models (Schumann et al, 2007) rather than as a parameter having physical meaning (Prasad et al, 1984). In fact, this coefficient is a model parameter that needs calibration in order to fit simulations to observations.

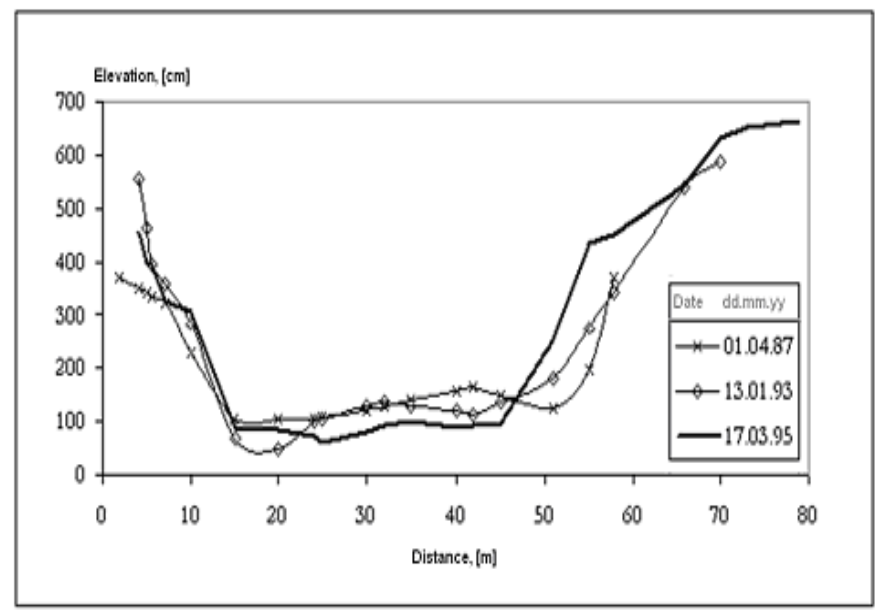

Figure 3. Evolution of the cross section geometry of the Slouguia's hydrometric station.

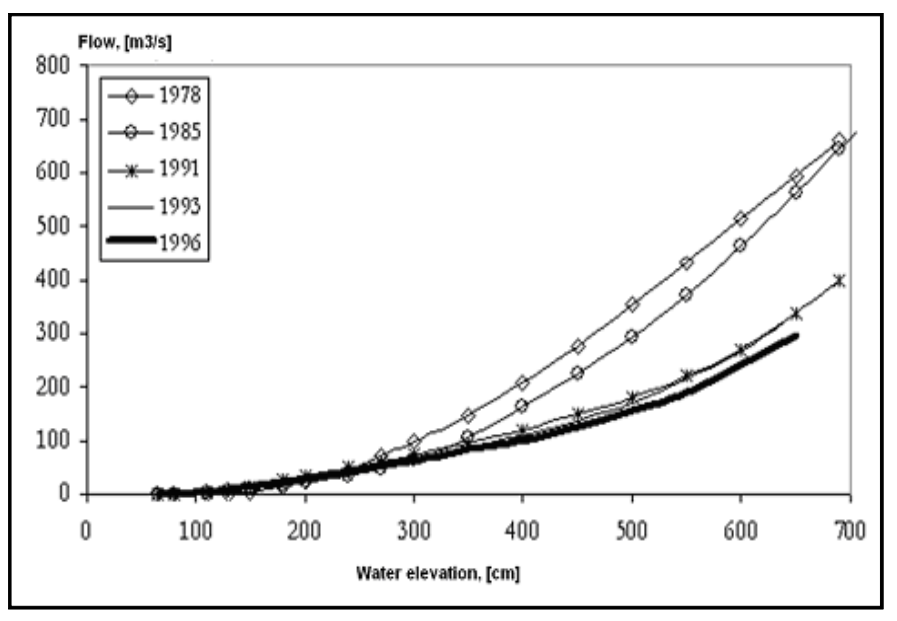

Figure 4. Evolution of the rating curve of the Slouguia hydrometric station.

HEC-RAS solves the conservation of mass and energy equations using the Preissmann's second-order scheme and the well known four-point implicit finite box differences scheme (Horritt et al, 2002). For this step, this model uses the Courant-number condition to avoid instability problems (USACE, 2002). The computation engine is based on the USACE's UNET developed by Barkau (1992, 1997). The used numerical scheme is marginally stable when run in a semi implicit form (Pappenberger et al, 2005). This form corresponds to a weighting factor of 0.5 for the unsteady solution (Nicholson scheme). However, due to its marginal stability for the semi-implicit formulation, a weighting factor of 0.6 or more is necessary. This increases the solution stability, but at the expense of solution accuracy. HEC-RAS defaults to a weighting factor of 1.0 (fully implicit, highly stable and highly diffusive) but allows the user to specify any value between 0.6 and 1.0 (Pappenberger et al, 2005).

The box finite difference scheme is limited in its ability to handle transitions between sub-critical and super-critical flow, since a different solution algorithm is required for each flow condition. To overcome this limitation, HEC-RAS employs a mixed-flow routine to patch solutions in sub-reaches (USACE, 2002).

\section{Modelling of Medjerda River}

The following input data are required to simulate flood routings and water level calculations using HEC-RAS: channel geometry; boundary and initial conditions, and channel resistance. In addition, it is necessary to have stream flow and water level data at key points along the modelled reach to assess the model performance. The geometric data consist of establishing connectivity of the river system, cross-section data, reach lengths, stream junction information and hydraulic structure data (e.g. bridges and culverts). Boundary conditions are specified for the two ends of the river reach (upstream and downstream). The upstream end of the river reach can be modelled with a flow hydrograph, a stage hydrograph, or both. The downstream end of the reach can be modelled based on the rating curve, normal depth, stage hydrograph, and flow hydrograph, or stage 
and flow hydrograph. In addition to the boundary conditions, the initial conditions (flow and stage) are required at all nodes at the beginning of the simulation. Channel resistance, Manning's friction coefficient, is the only calibration parameter required by the hydraulic model.

\section{Geometric Database}

Regardless of the model used for flood routing, accuracy of the simulation results depends on the quality of the available hydraulic and geometric data. For flood mapping, the topographical and bathymetric data are used for preparing geo-referenced data and for processing simulations results. Therefore, the river and the floodplain bathymetries must be accurately specified to minimize the uncertainties of the simulations. Several studies have shown that small errors in the topographic data may negatively affect the results of flood routing models (Pappenberge et al, 2005; Wilson, 2004 and Nicholas and Walling, 1998).

Topographical data were generated from a Digital Elevation Model (DEM) of the simulated area at the 1:50,000 scale. These data cover a reach extending from Sidi Salem's Dam to the Mediterranean Sea, a distance of $162 \mathrm{~km}$ when measured along the Medjerda centerline. They include 185 cross-sections profiles describing the main channel of the Medjerda river (Ghorbel, 1996), the lengths of the river reaches, and the characteristics of the main obstacles to the flow (fifteen bridges). The interpolation of the corresponding bathymetric data was accomplished using the cross section interpolation routine of HEC-RAS model (USACE, 2002). This routine is based on the string model, which is used to create more cross-sections and export them to Arc View software (ESRI, 1992-1999), to create a river terrain model. A detailed discussion on interpolating data of the main channels to create terrain models using this routine and the disadvantages of the corresponding string model can be found in Merwade et al. (2008). The integration procedure was performed using ArcView 3.2 which was then used to develop an accurate river DEM for the hydrodynamic modelling and flood risk mapping. First, we geo-referenced and processed the geographic field data. Second, we processed the geospatial data for HEC-RAS using ArcView extension HEC-GeoRAS 3.1 (USACE, 2002). The geometry set-up in HEC-GeoRAS extension involved digitizing the stream centerline, predicting overbank flow lines, levees, and a polygon coverage delineating roughness cover (Aggett et al, 2009). This extension was created using HEC-GeoRAS 3.1 import files containing geometric data from the DEM and complementary data sets. The longitudinal profiles of the study reach of the Medjerda main bridges are shown in Figure 5.

\section{Available Hydrologic Data}

River discharges of 350,400 and $450 \mathrm{~m}^{3} \mathrm{~s}^{-1}$ were used to calibrate HEC-RAS. These discharge data were collected by the Water Resources General Directorate (Ghorbel, 1996). Intensive field work was done to map some key cross-sections downstream of Sidi Salem Dam and to determine the discharge capacity of its main channel. During this work, a number of hydrometric gauging stations were operational, including: Slouguia, MedjezEl-Bab, El Herri, Borj Toumi, and Djedaïda located downstream of the dam.

Data from the 2003 flood was used to validate the calibrated HEC-RAS model. During this flood, the five hydrometric gauging stations previously mentioned were operational. The data collected consisted of hourly water stage from January $11^{\text {th }}$ to February $11^{\text {th }}, 2003$. The rating curves were used to determine the corresponding discharge.

The hydrograph of the dam outlet was used as the upstream inflow boundary condition for HEC-RAS 1-D. The discharge data at the other gauging station were used to validate HEC-RAS. The mean level of the Mediterranean Sea was taken as the downstream boundary condition. Tributary inflow data were ignored.

\section{Results and Discussion}

\section{Channel Resistance and Model Calibration Results}

Manning's function coefficient, $n$, is used to calibrate HECRAS. The final values of $n$ were $0.036 \mathrm{~m}-1 / 3 \mathrm{~s}-1$ for the upstream reach until Slouguia; $0.030 \mathrm{~m}-1 / 3 \mathrm{~s}-1$ for the middle reach which include Medjez El Bab, El Herri and Borj Ettoumi ; and $0.035 \mathrm{~m}-1 / 3 \mathrm{~s}-1$ for the downstream reach, from Diedaida until the Mediterranean Sea. The simulated water level compared favourably to measured values (Figure 6). Differences between measured and simulated values ranged from 1 and $9 \%$ with a mean difference of $4 \%$. These are reasonable results that are quite promising.

Although the simulated and measured water depths are similar, these Manning's coefficients should be used with caution since the floodplain roughness is usually higher than that of the channel. The resistance to flow decreases with increasing water level and, consequently, the effective relative roughness diminishes; however, it increases again once the flow spills the river overbank.

\section{Cartography}

The main goal of the numerical analysis is to test the models' ability to reproduce, at least qualitatively, the floodplains inundations extent caused by the events of 2003. The model performance was determined based on the observed traces of flooded zones. Sidi Salem Dam released flows during these events, and the discharges measured at Slouguia hydrometric gauging station, located $20.7 \mathrm{~km}$ downstream of Sidi Salem Dam, are shown in Figure 7.

From January 13th to February $17^{\text {th }} 2003$, the total released volume from the dam was $1.0 \times 109 \mathrm{~m}^{3}$. The total volume measured at Slouguia was $1.1 \times 109 \mathrm{~m}^{3}$. The difference between the two volumes, a $10 \%$ increase over the volume released from the dam, represents the contribution of the two main upstream tributaries: Siliana and Khalled Rivers. This contribution was included in the simulation.

The digital elevation model and the scheme of flood plain extension are depicted in Figure 8. The simulated water depth had reached more than two meters in some locations. The water ve- 


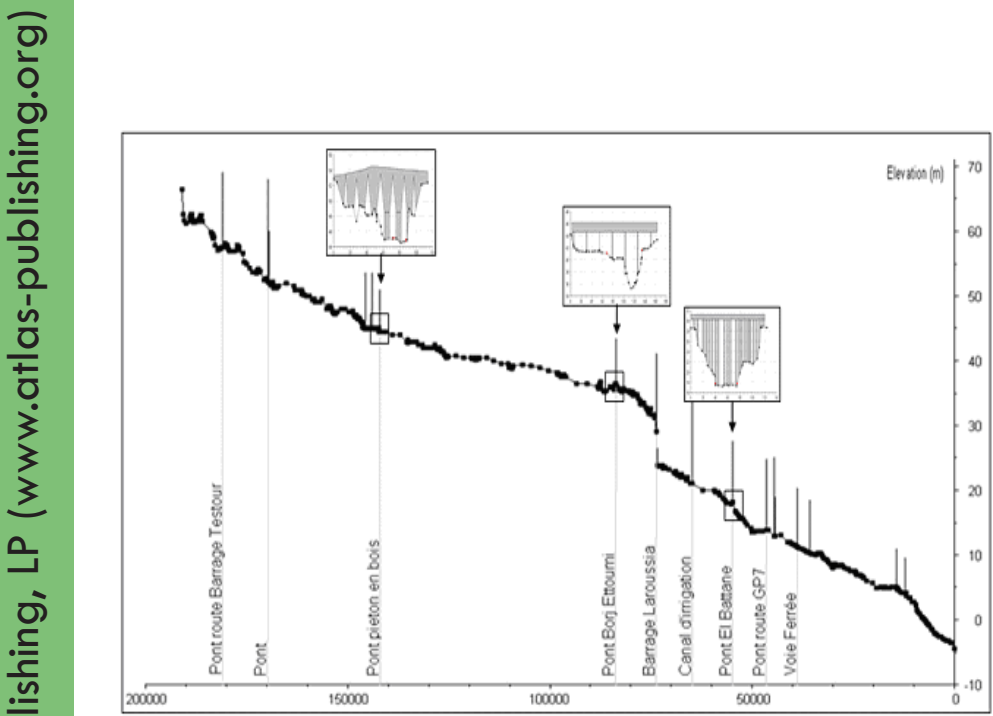

Figure 5. Medjerda River study reach longitudinal profile, distances upstream of the Mediterranean Sea, and main bridges locations.

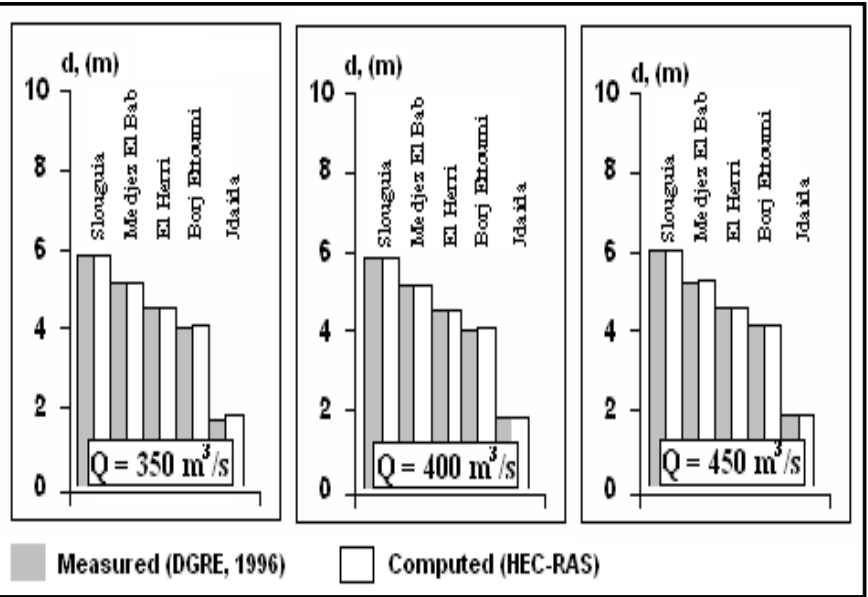

Figure 6. Water depth comparisons of HEC-RAS results and measured data.

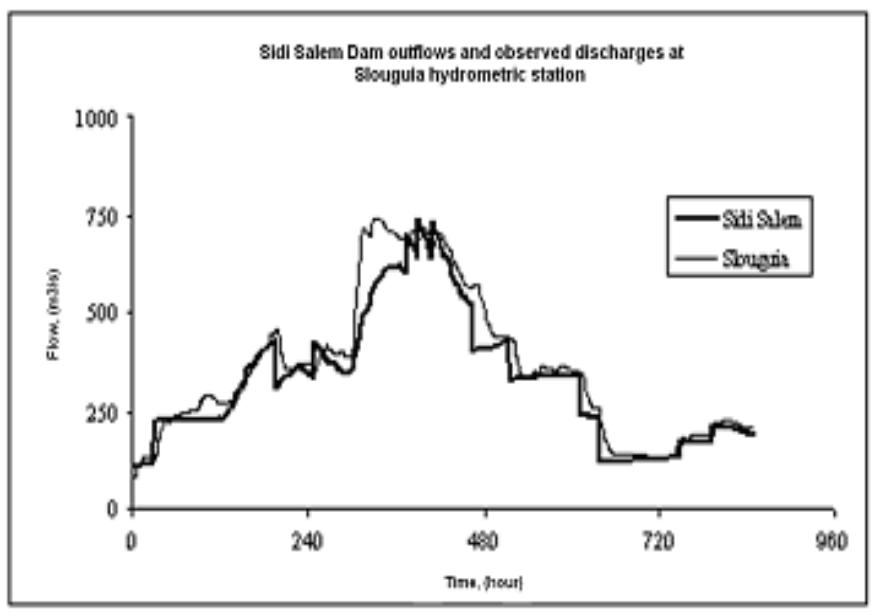

Figure 7. Sidi Salem Dam outflows and observed discharges at Slouguia station.

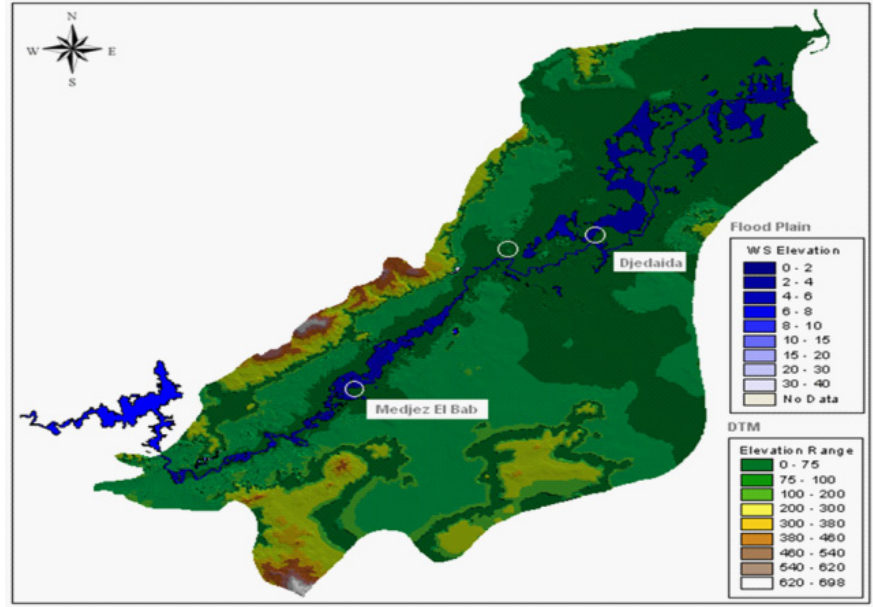

Figure 8. Simulated maximum extension of the flooded zone in 2003.

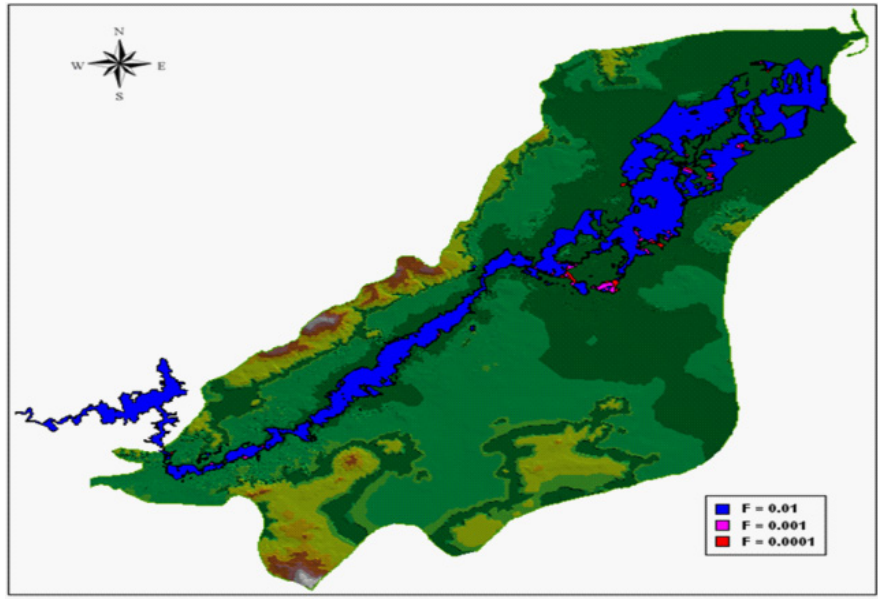

Figure 9. Extension of the flooded zones for some given frequencies.

locity was less than $0.5 \mathrm{~m} \mathrm{~s}^{-1}$. The flow regime was fuvial everywhere and partly explains the intensity of sediment deposition. The simulation results also predicted that the flood started at $\mathrm{EI}$ Matisse meandering zone, located about $10 \mathrm{~km}$ downstream of the town of Medjez-El-Bab. In this town, the overflows start from a flow of $700 \mathrm{~m}^{3} \mathrm{~s}^{-1}$. These results are quite comparable to the experimental observations. These results show that the model can be adequately calibrated and validated using hydrometric data. A reasonably calibrated and validated model is a useful tool that can be used to make adequate predictions of flood extents.

The calibrated validated HEC-RAS was then used to simulate three potential events released from the dam of the following frequencies: $0.01,0.001$, and 0.0001 , to map their corresponding flood zones. In order to estimate the discharges of these events, it was necessary to quantify their inflow flood hydrographs to the dam. These hydrographs were used as input for HEC-RAS to produce estimates of the extent of floodplain inun- 
dations. As shown in Figure 9, the low gradient of ground elevations, combined with the heavy outflows from the dam, would cause flooding in almost all parts of downstream Medjerda valley. The city of Medjez-El-Bab would be flooded starting from a flow of $1,200 \mathrm{~m}^{3} \mathrm{~s}^{-1}$. For the Medjerda reach downstream Laroussia until the sea, a flow of $1,000 \mathrm{~m}^{3} \mathrm{~s}^{-1}$ or more would lead to vast flooded zones. There too, the morphological imbalance of the natural river seems to play a major role in inundation aggravation.

\section{Conclusion}

This study reports on the evaluation of the numerical onedimensional water surface profile calculations model HEC-RAS. This model was calibrated and validated using historical field data. It was then used to simulate three potential flooding scenarios. Flooding zones of these scenarios were mapped. These results show a flooding potential for several areas downstream from the dam. The changes in the riverbed longitudinal profile and cross sections resulted in slower flow rates and large volumes of sediment loads. Such conditions expanded the potential flooding zones as a result of released water flows that did not cause flood in the past. The observations and the numerical simulations suggest further work to identify the exact locations of the areas of intervention, to locate the zones of hydraulic installations and to classify these installations by a set of priorities. We recommend immediate start of remedial measures which must be based on solid fundamental scientific field data.

\section{Acknowledgments}

The author thanks Mr Taoufik Abdelhedi and Mr. Abdelhamid Daoud of the General Directorate of Dams and Great Hydraulic of the Ministry of Agriculture for their collaborations. The author thanks the anonymous reviewers and the help of Samira Fares of the University of Hawaii-Manoa, and Dr Marouane Temimi of the City University of New York during the preparation of this manuscript.

\section{References}

Aggett G.R., Wilson J.P. (2009). Creating and coupling a high-resolution DTM with a 1-D hydraulic model in a GIS for scenario-based assessment of avulsion hazard in a gravel-bed river. Geomorphology 113, 21-34

Barkau, R.L. (1997). UNET: One-Dimensional Unsteady Flow through a Full Network of Open Channels, US Army Corp of Hydrologic Engineering Center, Davis, CA.

Barkau, R.L. (1992). UNET, One-dimensional unsteady flow through a full network of open channels, Computer Program. St. Louis, MO.

Ben Mansoura A., Garchi S., Daly H. (2001). Analyzing forest users' destructive behavior in Northern Tunisia. Land Use Policy 18, 153-163.

Bouraoui F., Benabdallah S., Jrad A., Bidoglio G. (2005). Application of the SWAT model in the Medjerda river basin (Tunisia). Physics and Chemistry of the Earth 30, 497-507.

Chow, V.T. (1959). Open-Channel Hydraulics. McGraw-Hill, New York.
Diebbi M., Marzouki A., Daouthi S., M'Rabet K. (2006). Numerical model of Medjerda flooding downstream of Sidi Salem Dam. Proceedings of the 7th Tunisia - Japan Symposium on Science, Society and Technology Sousse, Tunisia - 4-6 December 2006.

Diebbi M., Abdelhedi T. (2005). Etude numérique de la propagation des crues et de la gestion des barrages : Cas de la Medjerda. Journée Mondiale de l'Eau. 22 mars 2005, Hammamet, Tunisie

ESRI (1992-1999). ArcView GIS: Using ArcView GIS. Environmental Systems Research, Inc. Redlands, CA.

Ghorbel A. (1997): Dynamique fluviale de la Medjerda : Identification des points de débordements depuis le barrage de SIDI SALEM jusqu'à la mer. DGRE, 11 p.

Ghorbel A. (1996). Dynamique fluviale de la Medjerda. Analyse et interprétation des mesures des lâchers du barrage Sidi Salem. Ministère de l'Agriculture. Direction Générale des Ressources en eau, Rapport interne, 52 p.

Horritt M.S., Bates P.D. (2002). Evaluation of 1D and 2D numerical models for predicting river flood inundation. Journal of Hydrology 268, 87-99.

INAT, ESIER, DG.BGTH, DGRE, CRDA Beja, CRDA Manouba (2004) : Etude des risques $d$ inondations sur l'oued Medjerda.

Merwade V.M., Cook A., Coonrod J. (2008). GIS techniques for creating river terrain models for hydrodynamic modeling and flood inundation mapping. Environmental Modelling \& Software 23, 1300-1311

Mlayah A., Ferreira da Silva E., Rocha F., Ben Hamza Ch, Charef A., Noronha F. (2009). The Oued Mellègue: Mining activity, stream sediments and dispersion of base metals in natural environments, Northwestern Tunisia. Journal of Geochemical Exploration 102, 27-36.

Nicholas, A.P., Walling, D.E. (1998). Numerical modeling of floodplain hydraulics and suspended sediment transport and deposition. Hydrological Processes 12, 1339-1355.

Pappenberger F., Beven K., Horritt M., Blazkova S. (2005). Uncertainty in the calibration of effective roughness parameters in HEC-RAS using inundation and downstream level observations. Journal of Hydrology 302, 46-69.

Prasad T., Wakhlu O.N. (1984). Mathematical modelling for formation and propagation of floods in a data-deficient basin. Journal of $\mathrm{Hy}$ drology, 68, 311-329

Schumann G., Matgen P., Hoffmann L., Hostache R., Pappenberger F., Pfister L. (2007). Deriving distributed roughness values from satellite radar data for flood inundation modelling. Journal of Hydrology. 344, 96- 111

US Army Corps of Engineering, 2002: "HEC-GeoRAS. An extension for support of HEC-RAS using ArcView". Hydrologic Engineering Center.

US Army Corps of Engineering, 2002: "HEC-RAS. River Analysis System. Application guide version 3.1". Hydrologic Engineering Center.

US Army Corps of Engineering, 2002: "HEC-RAS. River Analysis System. Hydraulic Reference Manual Version 3.1".

US Army Corps of Engineering, 2002: "HEC-RAS. River Analysis System. User's Manual Version 3.1". Hydrologic Engineering Center.

Wilson MD. (2004). Evaluating the effect of data and data uncertainty on predictions of flood inundation. Southampton: University of Southampton. 276 pp.

Zahar Y., Ghorbel A., Albergel J. (2008). Impacts of large dams on downstream flow conditions of rivers: Aggradation and reduction of the Medjerda channel capacity downstream of the Sidi Salem dam (Tunisia). Journal of Hydrology. 351, 318- 330

Zar H. (2004). Etude des processus hydrosédimentaires - Application à la retenue du barrage de Sidi Salem. Mémoire de Mastère en Modélisation en Hydraulique et Environnement soutenu à l'ENIT. 